Article

\title{
Construction of Open Innovation Ecology on the Internet: A Case Study of Xiaomi (China) Using Institutional Logic
}

\author{
Jaime Ortiz ${ }^{1}$, Hao Ren ${ }^{2, *}, \mathrm{Kei} \mathrm{Li}^{3}$ and An Zhang ${ }^{4, *(\mathbb{C})}$ \\ 1 Vice Provost Global Strategies and Studies, University of Houston, E.W. Cullen Bldg. Suite 101, \\ 4302 University Dr., Houston, TX 77204, USA; jortiz22@uh.edu \\ 2 School of Economics and Management, Beihang University, Beijing 100191, China \\ 3 School of Economics and management, Tsinghua University, Beijing 100084, China; \\ liq.18@sem.tsinghua.edu.cn \\ 4 State Key Laboratory of Resources and Environmental Information System, Institute of Geographical \\ Sciences and Natural Resources Research, Chinese Academy of Sciences, Beijing 100101, China \\ * Correspondence: renhao@buaa.edu.cn (H.R.); zhangan@igsnrr.ac.cn (A.Z.)
}

Received: 13 May 2019; Accepted: 5 June 2019; Published: 11 June 2019

\begin{abstract}
The characteristics of collaborative innovation and interactions among core enterprises, users, and partners are critical. Research is lacking on how to construct open innovation ecology through institutional design. This study explores how core enterprises effectively motivate users and partners to participate in innovation activities on the Internet and successfully constructing open innovation ecology, using the institutional logic theory and an exploratory case study of Xiaomi, a famous Chinese Internet enterprise. The findings are as follows: (1) three main characteristics of innovation carried out by core enterprises, users, and partners in the open innovation ecology-iterative innovation, social innovation, and joint innovation; (2) three new institutional practices-following, leading, and symbiotic mechanisms - which provide an effective institutional guarantee for interaction and innovation; (3) two kinds of institutional logic-administrative logic and social logic, which core enterprises follow to construct open innovation ecology on the Internet, and its change in innovation characteristics. Therefore, a full understanding of the changing rules of the institutional logic is fundamental for successfully building open innovation ecology. This study enriches both the open innovation ecology theory as well as the institutional logic theory. In addition, Xiaomi's open innovation ecological development model proves that core enterprises can take the approach of building open innovation ecology. It provides a strong example to other enterprises on innovations on the Internet.
\end{abstract}

Keywords: open innovation ecology; institutional logic; Internet environment

\section{Introduction}

The integration of open innovation with an innovation ecosystem promotes the development of open innovation ecology [1]. On one hand, with the global rise of open innovation, users and enterprise partners are widely involved in and play an increasingly important role in all aspects of innovation [2]. In contrast, the network among the main participants in the innovation ecosystem gets increasingly robust as interactions become more frequent [3]. Thus, the innovation boundary between core enterprises, users, and enterprise partners is constantly blurred and the openness of the innovation ecosystem continues to increase [4]. In fact, the integration of open innovation and the innovation ecosystem is a new trend in enterprise innovation on the Internet. The core enterprise, users, and partners together constitute the open innovation ecology. 
The concept of open innovation ecology has been explored in both industry and academia. For example, IBM annually elicits innovative suggestions from global users through an online "Innovation Jam" to enhance its innovation ecosystem. Procter and Gamble has launched the "Network Alliance" project to streamline communication with its suppliers and consumers and has sought to incorporate their ideas into the life cycle of products [5]. Studies of effective research and development show however that if the company focuses too much on soliciting suggestions for innovation, it will lose its innovation advantage [6,7], because there is an extremely high cost to capturing and processing consumer and partner information, but only a small return in information with innovation value $[8,9]$. Moreover, not all users and partners are willing to participate actively in innovation of core enterprises [10], so core enterprises need to encourage them to participate in open innovation ecology [11].

Users and partners carry out innovative activities in the open innovation ecology, offering both an opportunity and a challenge for core enterprises where the key to the transformation of opportunities and challenges lies in coordinating their relationships [12]. Thus, clarifying the characteristics, mechanisms, and motivations of interaction and participation in innovation by core enterprises, users, and partners is important to the successful establishment of an open innovation ecology. Following the institutional logic theory, this article uncovers an exploratory case study of Xiaomi in China, a famous Chinese Internet enterprise with typical open innovation ecology characteristics, and analyzes the mechanism and implementation path by which the core enterprises effectively coordinate users and partners to innovate.

Institutional logic was applied to this case study method because (a) the existing literature on open innovation ecology has typically adopted resource-based or competitive strategy theories [13], whereas institutional branch-being one of the three main theories of enterprise strategic management theory (competition, resources and institution)—supplements existing research on the construction of open innovation ecology through institutional design; (b) it is an effective approach to analyzing internal relations between an organization and its members in a multifaceted context such as the rapidly changing Internet environment [14]; and (c) open innovation ecology is an extension of the innovation ecosystem theory under the increasingly popular open innovation paradigm [15]. At present, such research is still in a preliminary stage of examining new phenomena [16], therefore it is appropriate to use the exploratory case study method.

This study addresses the research question: How do core enterprises effectively motivate users and partners to participate in innovation activities on the Internet, thereby successfully building open innovation ecology? Specifically, (1) What are the characteristics of innovation among core enterprises, users, and partners in the process of building the open innovation ecology? (2) What mechanisms are effective in motivating users and partners to participate in innovation? And (3) what institutional logic do core enterprises, users, and partners apply to innovate and what are the implementation paths by which core enterprises successfully construct an open innovation ecology.

\section{Theoretical Background and Research Framework}

\subsection{Open Innovation Ecology}

Open innovation ecology, which integrates the innovation ecosystem and open innovation into a more complex system, is a current trend in scholarship [17]. Salmelin explains that, in comparison to an innovation ecosystem, open innovation ecology covers a broader range of innovation subjects, more frequent flow of innovative resources and more ecological innovation of the innovation chain in an open innovation paradigm [18].

Gupta et al. reported that core enterprises constantly compete with others in open innovation ecology to identify external innovation ideas, enhance their innovation capability, support new products, and meet customers' needs, which triggers a new round of innovation [19]. An important driving force in open innovation ecology results from synergies across the entire value chain of upstream and downstream enterprises, including research and development capabilities, consumers, strategic 
alliances, intellectual property rights, and managers [20]. Ecosystems where members share a common culture or stakeholder interests tend to most actively implement innovations [21]. Core enterprises play leading roles in the innovation ecosystem because they can make full use of internal and external resources for collaborative innovation to create and develop an open innovation ecology that meets the needs of various network members [22].

\subsection{Institutional Logic}

Institutional logic refers to the culture, beliefs, and regulations that guide how individuals and organizations think and behave, the assumptions and values that undergird their social interactions. It can form a fixed cognitive framework and be a standard for measuring legitimacy $[23,24]$. Organizational differences result from multiple coexisting institutional logics in a pluralistic institutional environment, emphasizing organizational reconstruction [25]. Previous research has established the foundations of institutional logic and debated the multiple requirements and complexity of the internal interactions of pluralistic institutional logics [26]. For example, Zhu et al. analyzed the convoluted relations between companies' social and business logics and constructed a theoretical model compatible with both set of logics [27]. Ren et al. researched the coexistence and development of cultural logic and manufacturing logic in the organizational ecology of Internet enterprises [28].

The focus of institutional practice research is the daily practices of individual actors who work to ensure the creation, maintenance, and transformation of institutions [29,30]. Practice usually refers to continuous regularization and frequent achievement [31]. The present study builds on the existing research regarding the behaviors and ways that institutional logic affects institutional practice [32-34].

\subsection{Research Framework}

Research on open innovation ecology is on the rise with the development of areas regarding open innovation and innovation ecosystem. Despite the fact that existing research on open innovation ecology is a new exploratory phenomena, the inquiry research on innovation ecosystem and open innovation still provides salient findings. Innovation ecosystem reexamines the conceptual system formed by innovation development from an ecology perspective [35]. For instance, Estrin divided innovation ecosystem into three innovation communities: research, development, and application [36]. Open innovation is put forward on the basis of reflecting on the traditional closed innovation, which focuses on innovation characteristics from four aspects: innovation subject, innovation platform, creative development and innovation environment [37,38]. In addition, Rohrbeck et.al thought that the research on open innovation ecology should be based on the stage of innovation [39].

Thus, this study draws on the research framework 'phenomenon-mechanism-cause' in combination with the 'mechanism-cause' research framework proposed by Tian et.al in the study of the operating causes of the business ecosystem [40], and the 'phenomenon-mechanism' research framework adopted by Yamakami [41] in the Apple Store operating system (see Figure 1). First, we analyze the components of the open innovation ecology that core enterprises construct on the Internet and the innovative characteristics of users and partners participating in the innovation ecology in order to answer this research question 1). Second, we analyze the institutional practices core enterprises use to ensure an effective participation by users and partners in innovation (that is, the 'mechanism' addressing research question 2). Third, through the institutional practice of a core enterprise, we identify the current institutional logic in the open innovation ecology—-that is, the 'reason', in order to answer this research question 3). Finally, from the perspective of core enterprise, we put forward the path to successfully construct an open innovation ecology on the Internet and compared its results with previous research. 


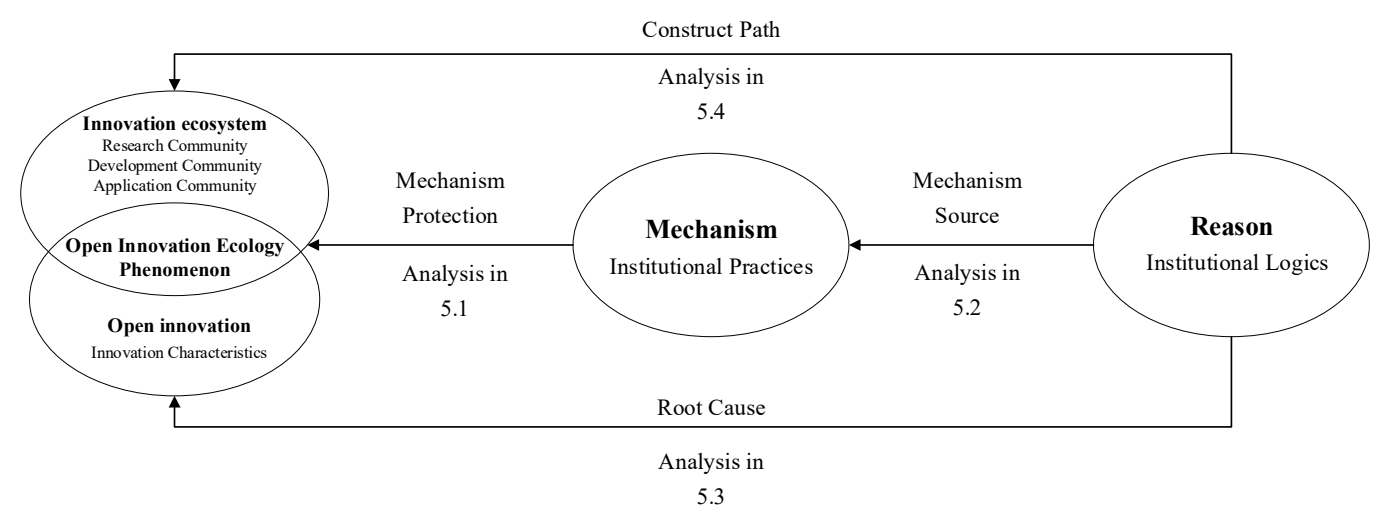

Figure 1. Research framework.

\section{Research Design}

\subsection{Research Method}

This study adopts the exploratory single case study method, the reasons are as follow: Firstly, an exploratory single case study was conducted to identify how core enterprises can effectively coordinate users and partners to build an open innovation ecology on the Internet. The case study approach is suitable for answering such "how" questions [42]. Since a case study captures rich qualitative data to deeply describe and analyze a particular phenomenon, it is useful for understanding the dynamic mechanisms behind the phenomenon, and particularly for observing and summarizing the evolution of internal management of enterprises [43]. Secondly, open innovation ecology resulted from the integration of the open innovation paradigm and innovation ecosystem theories, on which little research is extant. Exploratory case studies are useful in new research fields or where existing research problems are insufficient $[42,44]$. Finally, the research topic of this study needs to dig deeply into the selected cases, while a single case study can conduct case investigation and analysis in a deeper way [44]. Therefore, a single case study is conducive to better understanding the theoretical perspective used.

\subsection{Case Selected}

Xiaomi was chosen as the case study for three reasons grounded in theoretical considerations. First, as an innovative technology enterprise that independently researches and develops mobile phone operating systems, smart phones, smart hardware, and other products, Xiaomi is important and representative in the Chinese market. In addition, as a typical eco-strategy-driven enterprise, particularly with regard to open innovation and huge development potential on the Chinese Internet, Xiaomi has been rated among one of the world's top 50 innovative enterprises by the Boston Consulting Group and Fast Company. Therefore, the sample selection of Xiaomi meets the principles of being important and representative [45]. Second, the choice of Xiaomi conforms to the principle of theoretical sampling [46]. Xiaomi always follows the open innovation paradigm in its product $R \& D$ process so that its users and partners can give input into the innovation of various products and support its core open innovation ecology. In this regard the firm is markedly different from the closed innovation and single-mode innovation of many other high-tech enterprises. Third, ongoing organizational reshuffles have produced a great deal of data on evolutions in the way Xiaomi has constructed its open innovation ecology.

\subsection{Data Sources}

Following the principles of triangulation [47], data were collected from multiple sources [48], including in-depth interviews, internal and external materials, and direct observations. 
In-depth interviews of 90-180 min were conducted at Xiaomi from April 2017 to August 2018, and included 12 middle managers, senior personnel, or technical leaders in the Strategy, Human Resources, Product, Operation, Ecological Chain, and Information Departments. Five additional interviews were conducted with loyal users of Xiaomi products of various ages and from different regions of China. All interviews were recorded, and nearly 150,000 words were extracted from the recordings. In addition, several Xiaomi employees were pursuing their MBAs at Beihang University and Tsinghua University, we had the opportunity to guide their master's theses and learn about their experiences at the company. Some long-term employees provided valuable information since they had directly participated in the construction and management of Xiaomi's open innovation ecology. We interviewed them either in-person or by phone and summarized important information in writing after each interview.

We also collected a variety of internal and external materials through the Internet, journal articles, books, and other secondary materials. Internal information consisted of two Xiaomi-produced reports: "Sense of Participation" and "Field Notes on Xiaomi's Ecological Chain", as well as various internal data.

In terms of enterprise investigation, we made several site visits to Xiaomi for company tours, press conferences, and internal project discussions (see Table 1).

Table 1. Research data source list.

\begin{tabular}{|c|c|c|c|c|}
\hline \multicolumn{5}{|c|}{ In-Depth Interviews } \\
\hline \multicolumn{2}{|c|}{ Object } & Number & Time & Key Words \\
\hline \multicolumn{2}{|c|}{ Senior Management } & 2 & $90 \mathrm{~min}$ & Strategic Judgment \\
\hline \multicolumn{2}{|c|}{ Customer Operation Department } & 2 & $150 \mathrm{~min}$ & User Interaction \\
\hline \multicolumn{2}{|c|}{ Smart Phone Division } & 2 & $120 \mathrm{~min}$ & MIUI System \\
\hline \multicolumn{2}{|c|}{ Ecological Chain Products Division } & 2 & $120 \mathrm{~min}$ & Ecological Chain Management \\
\hline \multicolumn{2}{|c|}{ Technology R\&D Department } & 2 & $100 \mathrm{~min}$ & Technology Innovation \\
\hline \multirow{2}{*}{\multicolumn{2}{|c|}{$\begin{array}{c}\text { Product Design Department } \\
\text { Xiaomi Fans }\end{array}$}} & 2 & $90 \mathrm{~min}$ & User Experience \\
\hline & & 5 & $180 \mathrm{~min}$ & User Needs \\
\hline \multicolumn{5}{|c|}{ Internal and External Materials } \\
\hline Types & Number & \multicolumn{3}{|r|}{ Content } \\
\hline \multirow{5}{*}{$\begin{array}{l}\text { External } \\
\text { Materials }\end{array}$} & 2 & \multicolumn{3}{|c|}{$\begin{array}{l}\text { Monographs: "sense of participation", "field notes of } \\
\text { Xiaomi's ecological chain" }\end{array}$} \\
\hline & 30 & \multicolumn{3}{|c|}{ Research literature published } \\
\hline & 35 & \multicolumn{3}{|c|}{ Contents of speeches made by major managers in public } \\
\hline & 24 & \multicolumn{3}{|c|}{ Xiaomi's website, BBS related introduction } \\
\hline & & \multicolumn{3}{|c|}{ Other comments on Xiaomi's innovative model } \\
\hline \multirow{2}{*}{$\begin{array}{c}\text { Internal } \\
\text { Materials }\end{array}$} & 7 & \multicolumn{3}{|c|}{$\begin{array}{l}\text { Information of Xiaomi's application for technical } \\
\text { innovation awards }\end{array}$} \\
\hline & 18 & \multicolumn{3}{|c|}{ Xiaomi's employee training learning materials } \\
\hline \multicolumn{5}{|c|}{ Enterprise investigation } \\
\hline Time & Sites & \multirow{2}{*}{\multicolumn{3}{|c|}{$\begin{array}{l}\text { Content } \\
\text { Visit the headquarters of Xiaomi to understand the } \\
\text { development process and corporate culture }\end{array}$}} \\
\hline 18 April 2017 & Beijing & & & \\
\hline 10 January 2017 & Shanghai & \multicolumn{3}{|c|}{$\begin{array}{l}\text { Participate in offline activities organized by Xiaomi for } \\
\text { users to participate in, and investigate user operation }\end{array}$} \\
\hline 4 March 2018 & Beijing & \multicolumn{3}{|c|}{$\begin{array}{l}\text { Participated in the press conference of a certain mobile } \\
\text { phone model of Xiaomi to investigate and innovate } \\
\text { technology }\end{array}$} \\
\hline 7 May 2018 & Zhengzhou & \multicolumn{3}{|c|}{$\begin{array}{l}\text { Visit flagship store of Xiaomi and investigate user } \\
\text { experience and user demand }\end{array}$} \\
\hline 20 August 2018 & Beijing & \multicolumn{3}{|c|}{$\begin{array}{l}\text { Participated in the project discussion of an ecological } \\
\text { chain product of Xiaomi, investigated product R\&D and } \\
\text { technological innovation }\end{array}$} \\
\hline
\end{tabular}




\subsection{Reliability and Validity Strategy}

This article is an exploratory case study designed to discuss three indexes: constructional validity, extrinsic validity and reliability (see Table 2 ).

In terms of construction validity, we first went through in-depth interviews, internal and external materials, enterprise investigation and other data sources, in order to form a triangular verification to ensure the accuracy of data and consistency of views. The evidence chain in this study is formed through the process of "original data-statement discrimination-extraction of relevant constructs-preliminary construction and analysis of theory-further test and modification of theory and data-formation of theoretical model". Last but not least, in order to ensure the correctness of Xiaomi's mechanism and relevant data, we submitted the model to relevant personnel of Xiaomi for review and feedback.

In terms of external validity, we ensured the external validity in two ways: Firstly, through literature review and analysis, the theoretical analysis framework of this study is established to achieve a deep fit between the research and literature. Secondly, the open innovation ecology constructed by representative Xiaomi was selected as the research object.

In terms of reliability, this study improves the reliability by formulating a case study draft, establishing a database, repeating the implementation, and presenting multiple types of evidence.

Table 2. Strategies for ensuring reliability and validity.

\begin{tabular}{|c|c|c|c|}
\hline Inspection & Strategy & Phase & Specific Practices \\
\hline \multirow{3}{*}{$\begin{array}{l}\text { Construct } \\
\text { Validity }\end{array}$} & $\begin{array}{l}\text { Multiple data } \\
\text { sources }\end{array}$ & Data collection & $\begin{array}{l}\text { In-depth interviews, review of internal and } \\
\text { external materials, onsite observation and other } \\
\text { data sources to ensure the consistency of views }\end{array}$ \\
\hline & Data chain & Data collection & $\begin{array}{l}\text { Identification of key statements in original data, } \\
\text { extraction of relevant constructs, construction } \\
\text { and testing of a preliminary theory, modification } \\
\text { of theory in response to further testing and new } \\
\text { data, formation of theoretical model }\end{array}$ \\
\hline & Verification & Data collection & $\begin{array}{l}\text { Relevant personnel at Xiaomi review and give } \\
\text { feedback on the final model }\end{array}$ \\
\hline \multirow{2}{*}{ External Validity } & Existing theory & Study design & $\begin{array}{l}\text { Literature review and analysis confirm the } \\
\text { theoretical framework achieves a close fit } \\
\text { between the research and literature }\end{array}$ \\
\hline & Single case study & Study design & $\begin{array}{l}\text { The selection of research object has strong } \\
\text { representativeness }\end{array}$ \\
\hline \multirow{4}{*}{ Reliability } & Develop draft & Study design & $\begin{array}{c}\text { Research plan is reviewed with several } \\
\text { researchers and revised until a detailed research } \\
\text { plan is developed }\end{array}$ \\
\hline & Database & Data collection & $\begin{array}{l}\text { Data is coded in detail according to content, } \\
\text { means of acquisition, and time of acquisition }\end{array}$ \\
\hline & Repeat analysis & Data analysis & $\begin{array}{l}\text { Different researchers analyze the data separately, } \\
\text { compare and analyze the results, and reach } \\
\text { consensus after discussion }\end{array}$ \\
\hline & $\begin{array}{l}\text { Multiple types of } \\
\text { evidence } \\
\text { presented }\end{array}$ & Data Analysis & $\begin{array}{l}\text { The case study presents the data obtained from } \\
\text { internal documents, external materials, interview } \\
\text { content and other channels }\end{array}$ \\
\hline
\end{tabular}

\section{Case Findings}

\subsection{Background on Xiaomi}

Xiaomi was founded in April 2010 in Beijing, China, with a focus on high-end smart phones and under a smart home ecological chain construction of Chinese technology enterprises. Since its inception, it has already been awarded 4043 patents (1887 of them international), and has defined its 
mission to become an innovative technology enterprise that uses the Internet to develop intelligent hardware products.

In August 2010, Xiaomi launched its first product, the smartphone operating system MIUI, which broke the monopoly of iOS and Android in this arena. Not only was Xiaomi able to position itself for mobile Internet development, but it also garnered 500,000 loyal followers, laying a foundation for R\&D of mobile phone products. Currently, MIUI has 9 versions, with 300 million users, capabilities in 55 languages, and support in 142 countries and regions.

After developing its own operating system, Xiaomi launched its M1 mobile phone in August 2011. Subsequently, Xiaomi has generally released two or three new mobile phones each year (the M1 to M6, "Red Mi," Note, Max, and MIX series). Xiaomi's smartphones are the foundation of its technological innovation, corporate growth, and profitability. Take the M6 smartphone as an example: its screen technology has won 102 patents and it is widely popular with users, reaching 23.2 million phone shipments in the fourth quarter of 2018.

Despite the notable success of Xiaomi, competition in the smartphone industry is becoming progressively more intense, and the market increasingly saturated. Relying on a phone product is not conducive to the long-term growth of Xiaomi. Since the second half of 2013, has been investing in startup companies that develop smart hardware ("eco-chain products") and co-creating various products with them ("eco-chain companies"). About $85 \%$ of the eco-chain products can be directly controlled by the "Mi home" app on the Xiaomi smartphones.

\subsection{The Innovation of MIUI: Iterative Innovation}

In the process of developing MIUI, Xiaomi adopted an Internet product development model. Within this model in addition to engineering code writing, users can participate in other tasks such as suggesting product requirements, testing and releasing, and even partial development work. Most of the users who participated in the early MIUI's R\&D were "enthusiasts" of the mobile operating system, willing to use its recovery operating system, and experience new functions.

In order to involve enthusiasts fully in the R\&D process of MIUI, Xiaomi created the MIUI forum for the purpose of user interaction. The forum also allows Xiaomi to collect the enthusiasts' requirements, to receive feedback regarding functionality, and to publish updates relating to the MIUI.

Specifically, the MIUI updates are mainly divided into three versions: beta, developmental, and stable. The beta version is updated every day to deal with any Bugs identified through the enthusiasts' feedback, and only a limited number of enthusiasts have the right to perform this update. The developmental version is updated weekly, including the latest features of the enthusiasts' main requirements, and is released on the MIUI forum every Friday afternoon. The stable version is usually updated every 1 or 2 months by Xiaomi and its enthusiasts, being iterated and refined through the beta and development versions, and meeting the needs of the users to the greatest extent both in terms of new function development and bug repairs. Until now, Xiaomi has still been adhering to the MIUI's iterative development system and "Orange Friday" has been running for 355 weeks. Therefore, the innovation of MIUI is iterative innovation.

\subsection{The Innovation of Xiaomi Mobile Phone: Social Innovation}

Although Xiaomi has successfully introduced users to participate in innovation on the MIUI forum, there are still two deficiencies. The first is that the MIUI forum has many discussions on the professional issues related to its operating system, so the threshold for participation of ordinary users in innovation is higher. The second is that the development of mobile Internet has accelerated the popularity of social media through Wechat and Weibo, the largest Internet social media in China, to elicit suggestions for its products.

To make up for these shortcomings in the innovation of their mobile phone, Xiaomi expands the scope of users' participation in innovation through social media platforms that mainly include WeChat, Weibo. Unlike the MIUI forum that focuses on new functions and new technology innovation, 
these users are more likely to use social media for making suggestions based on their experience of the phone, such as product quality, appearance and usage skills. However, questions remain concerning how Xiaomi uses social media tools for user innovation, and why users are willing to participate in Xiaomi's innovation.

Xiaomi WeChat has reached 10 million users and Xiaomi Weibo has 30 million users. Therefore, Xiaomi regularly releases some interesting content related to mobile phones on WeChat and Weibo to attract users. These users offer their own suggestions about the products when they participate in content discussions. For instance, Xiaomi once posted a topic called "I am a Phone Freak" on Weibo to get users to change their old mobile phones. In a short time, more than 1 million users replied to this topic and it generated over 17 million comments. While reviewing the history of the mobile phone, the users also discuss the Xiaomi mobile phone, so Xiaomi gains creativeness from users. Therefore, the innovation of Xiaomi mobile phone is social innovation.

Faced with a significant amount of feedback from users on social media platforms, Xiaomi could not respond to one by one, but it reprocessed the feedback through data mining, and finally generated the Top 10 recommendations with the highest frequency of user responses. For example, Xiaomi set up an API interface in WeChat and developed a special customer service backstage. The problem of user feedback could be automatically addressed by keyword recognition. This resulted in only $10 \%$ of the total feedback needing to be processed by humans. In addition, Xiaomi set up a quality committee composed of senior executives to deal with the Top 10 recommendations. The quality committee meets weekly to discuss what improvements to act on from the Top 10 recommendations.

\subsection{The Innovation of Ecological Chain Products: Joint Innovation}

Xiaomi started with MIUI and then developed hardware through Xiaomi mobile phones. It has many core technologies in the soft and hardware of smartphones, but lacks experience in developing other smart hardware.

Therefore, Xiaomi decided to develop ecological chain products. In this process, new partners must be introduced. In the process of introducing new partners, Xiaomi has found that most of these companies adopt traditional mergers and acquisition approaches through research on Google, Facebook, Microsoft and other Internet companies. The disadvantages of the acquisition model are three-fold. The first is that the companies that have been acquired will lack the enthusiasm to continue with innovation following receipt of the investment funds. The second disadvantage is that, as the merged companies are affiliated with the parent company, they therefore lose their independence, so they are not conducive to continuous innovation after the merger and acquisition. Thirdly, it can be difficult to maintain consistency between the parent and the merged companies in terms of product concept and design.

Therefore Xiaomi introduces partners through a new and more open model. Xiaomi implements the system of "the US Pentagon-special forces". First of all, Xiaomi as "the US Pentagon", provides the product definition and industrial design innovation support to the ecological chain company. In terms of product definition, Xiaomi is good at industrial design, so it guides the ecological chain companies to innovate in product design. According to the statistics, $70 \%$ of the eco-chain products come from the design of Xiaomi.

Secondly, ecological chain companies, as "special forces", only need to focus on the familiar intelligent hardware field, and innovate and develop one new ecological chain products. For instance, the intelligent water purifier developed by YunMi (an ecological chain company) has more than 400 patents, including more than 100 invention patents. The innovation rate of components and parts is over $90 \%$. There are 3 sets of plans for trial and error in the process of R\&D, and nearly 20 kinds of raw materials are mixed in different proportions. More than 300 kinds of materials are deployed and tested in 3 sets of molds. These achievements cannot be made without the abundant resources of Xiaomi and the professional technology of YunMi. 


\section{Discussion}

This study follows the "phenomenon-mechanism-reason" logical progression from shallow to deep analysis. The case analysis is divided into three parts: (1) the composition of Xiaomi's open innovation ecology and the characteristics of interactive innovation; (2) the institutional mechanism that sustains the development of open innovation ecology, (3) the essence of the phenomenon, and the institutional logic and implementation path behind Xiaomi's successful construction of open innovation ecology.

\subsection{Composition and Interactive Innovation Characteristics of Xiaomi's Open Innovation Ecology}

Three kinds of products constitute the basis of Xiaomi's open innovation ecology: the Xiaomi mobile phone series, MIUI 1 to 9 versions of the mobile phone operating system, and the "ecological chain products" of intelligent hardware compatible with mobile phones.

The open innovation ecology of core enterprises into three innovation communities: research, development, and application [36]. In Xiaomi case, MIUI is the core on which the diverse functions of Xiaomi's mobile phones rely. The "Mi home" app on the mobile phone controls $85 \%$ of the ecological chain products, and the ease of use of MIUI directly determines the user's experience of the ecological chain products. Therefore, MIUI is the research foundation of innovation ecology. As the carrier of MIUI, the Xiaomi mobile phone is also the main entrance into the ecological product chain, which forms a continuous link in Xiaomi's innovation. Therefore, the Xiaomi mobile phone is the development and the result of the implementation of the innovation ecology. Ecological chain products further expand the scope of Xiaomi's innovation and it is the basis for the application of innovation ecology.

In summary, Xiaomi's open innovation ecology is similar to a series of concentric circles. The MIUI 1-9 operating systems, Xiaomi mobile phone series, and ecological chain products correspond to the research community, the development community, and the application community, respectively. These three communities are closely linked, jointly promoting sustainable development of innovation ecology (see Figure 2).

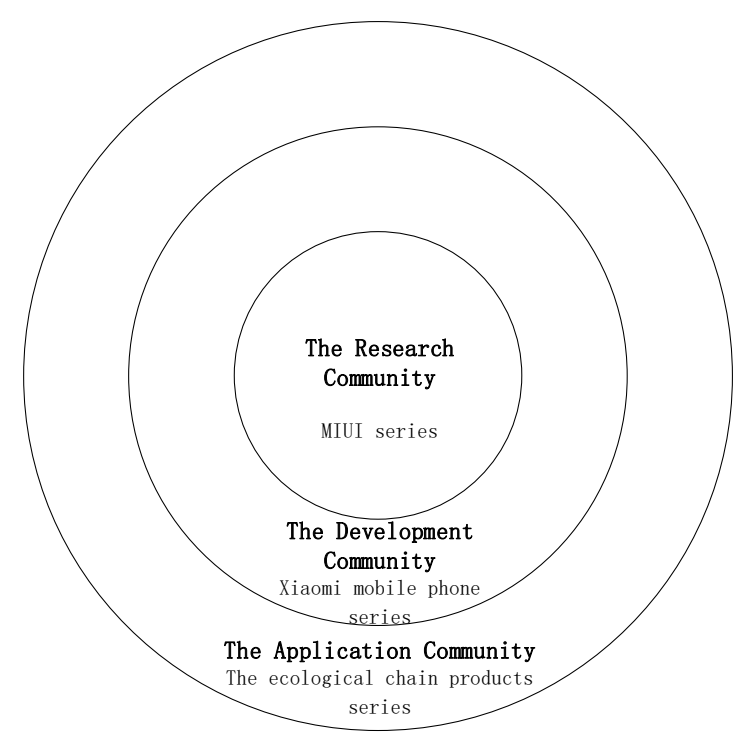

Figure 2. The three research communities of Xiaomi's open innovation ecology.

Although the three communities are closely linked, each has unique characteristics. Specifically, this study analyzes the differences among various innovative communities in Xiaomi's open innovation ecology from three perspectives: innovative products [49], innovation subject [50] and innovation platform [51]. Accordingly, we find out the research community has the innovative characteristics 
of iterative innovation; the development community shows the innovative characteristics of social innovation; the application community has the innovative characteristics of joint innovation (see Table 3 ).

Table 3. The innovative characteristics of Xiaomi's open innovation ecology.

\begin{tabular}{ccccc}
\hline $\begin{array}{c}\text { Innovation } \\
\text { Community }\end{array}$ & $\begin{array}{c}\text { Innovative } \\
\text { Product }\end{array}$ & $\begin{array}{c}\text { Innovation } \\
\text { Subject }\end{array}$ & $\begin{array}{c}\text { Innovative } \\
\text { Platform }\end{array}$ & $\begin{array}{c}\text { Innovative } \\
\text { Characteristic }\end{array}$ \\
\hline $\begin{array}{c}\text { Research } \\
\text { Community }\end{array}$ & MIUI & $\begin{array}{c}\text { Enthusiasts and } \\
\text { Xiaomi }\end{array}$ & MIUI forum & $\begin{array}{c}\text { Iterative } \\
\text { Innovation }\end{array}$ \\
\hline $\begin{array}{c}\text { Development } \\
\text { Community }\end{array}$ & $\begin{array}{c}\text { Xiaomi mobile } \\
\text { phone }\end{array}$ & $\begin{array}{c}\text { Common users and } \\
\text { Xiaomi }\end{array}$ & $\begin{array}{c}\text { Social network } \\
\text { (WeChat, Weibo) }\end{array}$ & Social Innovation \\
\hline $\begin{array}{c}\text { Application } \\
\text { Community } * * *\end{array}$ & Eco-chain products & $\begin{array}{c}\text { Eco-chain } \\
\text { companies and } \\
\text { Xiaomi }\end{array}$ & $\begin{array}{c}\text { Platform of } \\
\text { investment and } \\
\text { hatching" }\end{array}$ & Joint Innovation \\
\hline
\end{tabular}

Notes: * Data support: The MIUI system is constantly changing, but the constant is that it is a living system that even now still requires weekly updates. ${ }^{* *}$ Data support: Xiaomi currently invests hundreds of people in maintaining social media platforms, which we regard as the most important innovation platform. ${ }^{* * *}$ Data support: The "investment and hatching" platform gives ecological chain companies more energy to continue to help them grow.

\subsection{Institutional Practices Promoting the Development of Xiaomi's Open Innovation Ecology}

As the previous discussion showed, the three communities of Xiaomi's open innovation ecology have obvious differences in innovative products, innovation subjects, and innovation platforms, reflecting the differences in innovative characteristics. What kinds of institutional practices are needed to guarantee these different innovative characteristics? How do these institutional practices contribute to the open innovation ecology of Xiaomi? To answer these questions, we analyze the institutional practices of Xiaomi's open innovation ecology.

Xiaomi has adopted the following mechanism adapted to the rhythm of iterative innovation of MIUI, enhancing the innovation speed of the research community. In terms of products, Xiaomi's new MIUI iterations are released in three phases: beta version, development version, and stable version. This method meets users' demands for rapid evolution. In terms of organization, Xiaomi has "Internet Development Team" institutional. The team members, who are users of MIUI, are largely enthusiasts of mobile operating systems and of Xiaomi. The advantages of the Internet Development Team are that as many as 100,000 people may contribute their talents to promote a rapid evolution of new MIUI versions through the three development phases, and they ensure MIUI innovations are consistently based on the needs of users.

Data support: We logged in to the MIUI forum every week. According to our internal requirements, Xiaomi engineers must respond to the user's questions as long as the user's feedback concerns either a bug or a new feature. In addition, if a user puts forward some good ideas on the MIUI forum, in the next half month or month, he/she can see the ideas realized in the new version of the MIUI system.

\section{—Weixing. Li, director of MIUI system}

Xiaomi adopts a leading mechanism that effectively eliminates the interference caused by invalid information and enhances the innovation efficiency of the development community. Firstly, Xiaomi has instituted its online social media platform in order to expand the range of users. For example, WeChat and Weibo, which all have a large number of subscribers, are used to attract users. Secondly, through social media platforms, Xiaomi has introduced a series of topics and activities that increase users' engagement, such as "I am a mobile phone freak," "150 grams of youth" on Weibo, the "I love the Xiaomi mobile phone" activity on WeChat. Finally, as Xiaomi introduces a large number of users to social innovation, it is inevitable that many niche needs or unrealistic ideas will emerge. However, Xiaomi uses big data mining to summarize user feedback collected from social media platforms and 
identify ideas that have a high degree of user support; thus, innovation is directed to areas where user demand is strongest.

Data support: When the user community expands from enthusiasts to mass users, perhaps $90 \%$ of the suggestions are non-professional recommendations, so it is not realistic that we implement all the users' needs. Therefore, we will select several ideas with the most demanding implementation requirements, and this approach is acceptable to users.

-Wanqiang. Li, cofounder of Xiaomi

The application community is characterized by joint innovation. Xiaomi has adopted symbiotic relationships with ecological chain companies as an institutional practice to realize the innovation of ecological chain products. Xiaomi not only provides funds and opens channels to the ecological chain company (its "special forces"), but also helps that company to define its products and improve its industrial design. In return, the ecology chain company needs only to continue innovate its own technology with Xiaomi's support, until it finally develops a competitive piece of smart hardware. This symbiotic mechanism reduces the inherent risks in technological innovation for the eco-chain company, while reducing the cost of developing intelligent hardware for Xiaomi. The mutual benefit created makes innovation of new applications more sustainable (see Figure 3).

Data support: Xiaomi has invested in ecological chain companies and has always held only small shares in them. This behavior guarantees the independence and vigor of the team because our core idea is to replicate the successful model of Xiaomi with a batch of companies in the intelligent hardware field. In such an ecological environment, capital is only a link to build relationships, and the transmission of values, product concepts, and methodologies is the foundation for the entire ecosystem to be able to reproduce.

—De Liu, co-founder of Xiaomi

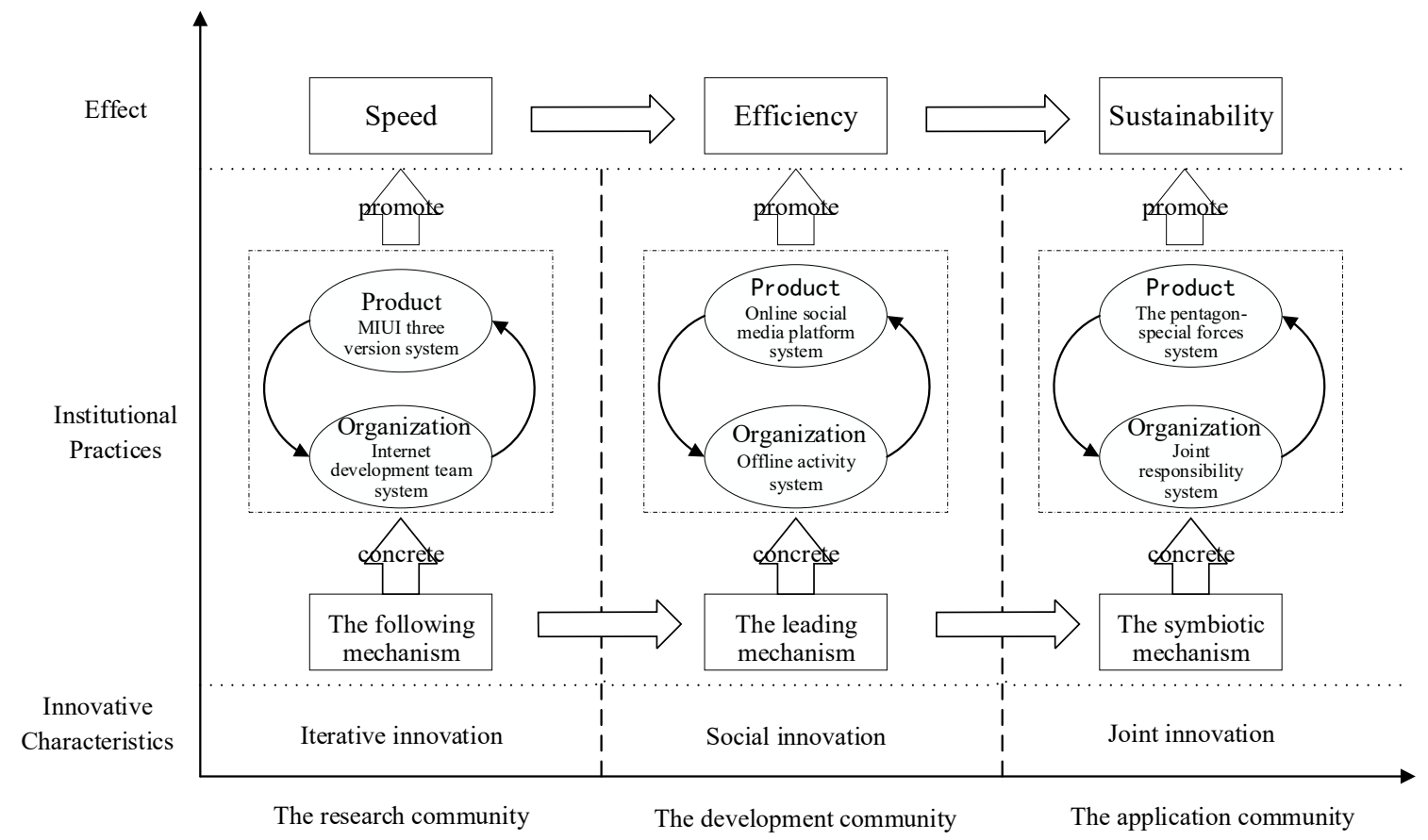

Figure 3. Institutional practices of Xiaomi's open innovation ecology.

\subsection{Varieties of Institutional Logic Underlying Xiaomi's Successful Construction of Open Innovation Ecology}

Changes in institutional logic mainly address how institutional practices emerge, change, and disappear [52]. Therefore, only by identifying the institutional logic extant in the multi-innovation 
environment can we find the root cause of the successful construction of Xiaomi's open innovation ecology.

It became clear that in Xiaomi's open innovation ecology, innovation stems from two forces. One of the partners in the innovation is an internal Xiaomi employee, and the others come from the online community and what the eco-chain companies contribute. Hence, we define the behavioral motives of Xiaomi's internal innovation activities as an administrative logic that serves to guide innovation through the intervention of the company's administrative power and establishment of rules and regulations. Administrative logic derives from dominant logic, which is a management tool to conceptualize business matters, achieve certain goals, and make key resource allocation decisions [53]. Meanwhile, the behavioral motivations of the enthusiasts, and ordinary users of Xiaomi products, and of the eco-chain companies are explained by social logic; that is, by reliance mainly on strengths outside the core enterprise to guide innovation. Concepts similar to the social logic have been proposed in many previous studies of institutional logic [54,55].

However, there are two dominant social and administrative logics embedded in Xiaomi's open innovation ecology, which are expressed differently depending on the environments [56]. The institutional logic has a relatively stable dominant logic in a given environment but as the environment changes, so will the dominant logic [34]. Thus, the social logic and the administrative logic change with the type of innovation communities in the open innovation ecology (see Table 4).

Table 4. Evolution of institutional logic in Xiaomi's open innovation ecology.

\begin{tabular}{|c|c|c|}
\hline $\begin{array}{c}\text { Innovation } \\
\text { Communities }\end{array}$ & Dominant Institutional Logic & Data Support \\
\hline $\begin{array}{l}\text { Research } \\
\text { Community }\end{array}$ & $\overbrace{\begin{array}{c}\text { The social } \\
\text { logic }\end{array}}^{(20}$ & $\begin{array}{l}\text { "Our mechanism plays a very positive role in innovation, } \\
\text { because we use the Internet iterative model to innovate. } \\
\text { Where users think we need to improve, we try to achieve it } \\
\text { and see the responses of the users. We'll leave the good } \\
\text { innovation that the users reflect. If it is not good enough, } \\
\text { it should be modified until the users satisfied."- Weixing. Li, } \\
\text { director of MIUI system }\end{array}$ \\
\hline $\begin{array}{l}\text { Development } \\
\text { Community }\end{array}$ & The administ & $\begin{array}{l}\text { "The relationship between users and Xiaomi is not just about } \\
\text { buying and selling, it is that the users are deeply involved in } \\
\text { Xiaomi's growth, and have built a deep relationship with } \\
\text { Xiaomi. We interact with users, whether it is online or offline, } \\
\text { no matter when, we're thinking about how to get users } \\
\text { involved. Let them become the "big stars" of product } \\
\text { improvement and innovation with the official team of } \\
\text { Xiaomi."-Wanqiang. Li, cofounder of Xiaomi }\end{array}$ \\
\hline $\begin{array}{l}\text { Application } \\
\text { Community }\end{array}$ & $\begin{array}{c}\text { The } \\
\text { Administrative } \\
\text { logic }\end{array}$ & $\begin{array}{l}\text { "The innovation of MIUI and the Xiaomi mobile phone seeks } \\
\text { to find the fans of Xiaomi, and make them participate in the } \\
\text { process of R\&D of the product. The eco-chain product is made } \\
\text { by those who trust the Xiaomi model. Xiaomi empowers them, } \\
\text { lets them work with Xiaomi to lead the product research and } \\
\text { development. The former is developed by Xiaomi's fans and } \\
\text { users; the latter is developed by Xiaomi's partners to co-lead } \\
\text { the product with Xiaomi."- De Liu, co-founder of Xiaomi }\end{array}$ \\
\hline
\end{tabular}

In the research community, social logic is the dominant institutional logic. The innovative product of the research community is MIUI. During the R\&D of MIUI, Xiaomi has always innovated by responding to users' ideas and suggestions, then formulating the next mechanism to guarantee innovation. Xiaomi expects MIUI engineers to answer users' questions appearing on the MIUI forum daily, and to give feedback on users' ideas at a response rate of $90 \%$ which proves that Xiaomi values and supports user-led innovation. Moreover, the MIUI Internet Development Team consists of about 1000 Xiaomi engineers, and the rest are mostly fans and enthusiasts.

In the development community, however, administrative logic is the dominant system logic. The innovative product of the development community is the Xiaomi mobile phone. Xiaomi drives 
innovation by mobilizing users to make recommendations about the phone, then compiling those suggestions. The company then selects the most frequent suggestions as the focus of innovation. Xiaomi also actively organizes users to participate in offline activities as a way to engage in innovation. In addition, unlike in the MIUI innovation process, Xiaomi sets up a leading mechanism to promote innovation. In the collection of external opinions Xiaomi actively seeks ideas and suggestions on social media platforms, rather than relying on enthusiasts and fans who are self-motivated to offer their ideas on the MIUI forum.

Finally, in the application community Xiaomi balances social logic with administrative logic. The innovative product in this community is the ecologic chain product. In the process of innovation, Xiaomi and the ecologic chain companies have established complementary advantages and mutual benefits, achieving a win-win status for the "the US Pentagon special forces" through the principles of "joint responsibility," "investment not holding," and a "brother company" relationships. Therefore, in the innovation of ecological chain products, power is shared between the core enterprise and the external ecological chain companies, and a balance between social logic and administrative logic predominates in the application community.

\subsection{The Path by Which Core Enterprises Can Construct an Open Innovation Ecology}

Institutional logic theory divides the open innovation ecology of core enterprises into three innovation communities: research, development, and application. Each innovation community contains four elements: dominant institutional logic, institutional practice, innovation characteristics, and innovation function. The core enterprise first needs to identify the dominant institutional logic of each innovation community, then effectively implement that institutional logic in practice, and finally modify its form to suit the characteristics of the innovation community. Eventually, the three innovation communities become integrated in one ecosystem where each plays a different role; at this point the three innovation communities are interlocking and co-evolving, driving the development of open innovation ecology such as a caterpillar (see Figure 4).

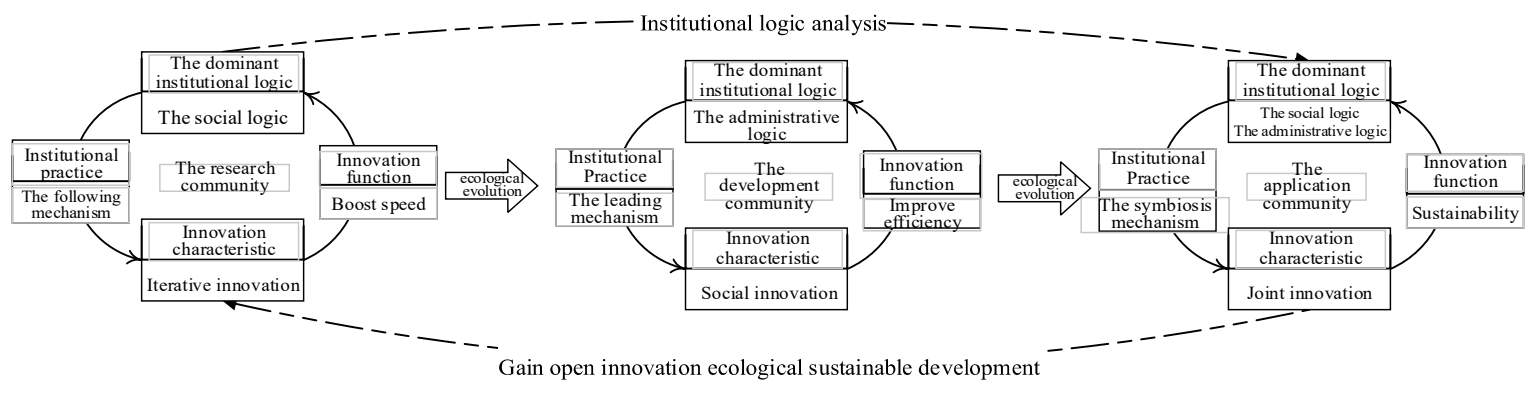

Figure 4. Xiaomi's open innovation ecology development model based on institutional logic theory.

Previous research on the open innovation ecology mainly focuses on concept definition $[20,21,39,57]$ and driving factors $[15,58]$. Few studies have focused on construct, especially construct paths and mechanisms. This article considers a case study of Xiaomi, a Chinese Internet enterprise with typical ecology, and explains the causes and path for the open innovation ecology constructed of a core enterprise from the perspective of institutional logic theory. The novelties are as follows: (1) The previous research perspective focuses on the macro descriptions and the analysis of influencing factors. This research takes the micro-perspective into the internal innovation activities. Based on the Xiaomi's open innovation ecology development model (see Figure 4), this paper opens up the "black box" of the internal construct of Internet enterprises at the micro level, complementing the macro studies in the literature. (2) The previous research context is mostly based on the Western Internet enterprise. However, China as the country with the fastest development of Internet market, previous research on the open innovation ecology of China's Internet environment is lacking, while this article studies 
Internet enterprises in China. (3) This research method is based on an exploratory case study rather than an empirical one which still allows for explaining the new phenomenon of the open innovation ecology.

\section{Conclusions}

How can core enterprises effectively coordinate users and partners to participate in an open innovation ecology? This question has never been settled in theory [59]. This case study of Xiaomi's open innovation ecology offers the following conclusions.

(1) There are three main characteristics of innovation carried out by core enterprises, users and partners in open innovation ecology: iterative innovation, social innovation, and joint innovation. Iterative innovation refers to the innovative way that the core enterprise improves its products repeatedly according to user suggestions in order to better meet users' needs. Social innovation means that core enterprises maintain good communication with users through online social media and offline activities, actively solicit users' innovative ideas on products, and carry out targeted improvement through interactive communication. Joint innovation means that core enterprises jointly develop products through cooperation with partners based on complementary advantages and mutual benefits.

(2) We propose three new institutional mechanisms-following, leading, and symbiotic - that a core enterprise uses to effectively coordinate with users and partners participating in innovation within an open innovation ecology. The following mechanism guarantees iterative innovation, which primarily manifests in the core enterprise regularly updating its products, integrating innovative suggestions put forward by users in new versions of these products as quickly as possible. The leading mechanism guarantees social innovation, which is a set of institutions in which core enterprises actively prompt users to participate in innovation. Its key feature is that core enterprises determine the parameters of users' participation in product innovation, whether improvement suggestions are adopted, and what form, scale, and types of user organizations will participate in innovation activities. A symbiotic mechanism guarantees joint innovation, which is an institutional philosophy that ensures resource sharing, information sharing, and risk sharing between the core enterprise and its partners in the processes of joint research and development.

(3) This study has identified administrative logic and social logic as two kinds of institutional logic that core enterprises follow in constructing open innovation ecology on the Internet, and the choice between the two varies depending on the context of innovation. When acting in accordance with administrative logic, the core enterprise guides innovation through imposing its authority and formulating rules and regulations. When innovating through the logic of social forces, the core enterprise acts to involve external users and partners. Furthermore, we conclude that the fundamental requirement for a successful construction of open innovation ecology is that the core enterprise accurately grasps the changing rules of multi-institutional logic. In this case, the dominant institutional logic that iterative innovation should follow is social logic, the dominant institutional logic that social innovation should follow is administrative logic, and joint innovation should achieve a balance between the two in research and development.

The theoretical contribution of this article lies in identification of the conceptual link between open innovation ecology and institutional logic, which provides a foundation for scholars to study the new concept of open innovation ecology from the institutional perspective. This study put institutional logic and open innovation ecology into a research framework in which institutional logic, institutional practice, and innovative features are closely related, and only their mutual adaptation can promote the development of open innovation ecology. Meanwhile, these research conclusions also have significant implications for the innovation practice of other enterprises. Following, leading, and symbiotic mechanisms provide a set of feasible management methods for core enterprises to effectively coordinate users and partners to participate in the open innovation ecology. Furthermore, the Xiaomi's open innovation ecology development model, based on institutional logic, for closed-loop analysis of the ecological construction path, it is able to provide experience for construction open innovation ecology of other Internet enterprises. 
This paper offers some limitations that leave two aspects for future research: (1) This article uses Xiaomi because of its large-scale Internet background and most obvious open innovation ecology characteristics. Most importantly, it has abundant human resources and the ability to motivate users and partners to participate in innovation activities on the open innovation ecology. However, how should we build open innovation ecology for small and medium-sized Internet companies? We will further collect and analyze other companies in future research, conducting a multiple-case study to complete and improve the conclusions of this study. (2) The research method of an exploratory case study is not an empirical, and builds on a model based on interview data and theoretical analysis. Our following research will quantitatively test the results of this paper.

Author Contributions: As the primary authors, J.O. and H.R. initiated the case study, performed the analysis, and wrote the paper. K.L. contributed in structuring and editing the paper, and proofreading the manuscript. A.Z. supervised and provided advice on this case study.

Funding: This article was granted by Chinese Academy of Sciences, grant number [XDA19040402]; National Key Research and Development Program of China, grant number [2017YFB0503500]; Featured Institute Construction Services Program, grant number [TSYJS03], and China Scholarships Council, grant number [201806020101].

Acknowledgments: The authors are grateful to the editor and anonymous referees for helpful comments and suggestions.

Conflicts of Interest: The authors declare no conflict of interest.

\section{References}

1. Radziwon, A.; Bogers, M. Open innovation in SMEs: Exploring inter-organizational relationships in an ecosystem. Technol. Forecast. Soc. Chang. 2018, 2017, 16692. [CrossRef]

2. Cui, A.S.; Wu, F. Utilizing customer knowledge in innovation: Antecedents and impact of customer involvement on new product performance. J. Acad. Mark. Sci. 2016, 44, 516-538. [CrossRef]

3. Barchi, M.; Greco, M. Negotiation in Open Innovation: A Literature Review. Group Decis. Negot. 2018, 27, 343-374. [CrossRef]

4. Wikhamn, B.R.; Styhre, A. Open Innovation Groundwork. Int. J. Innov. Manag. 2019, 2050013. [CrossRef]

5. Group, E. What do Apple, IBM and P\&G know: How open innovation can help business-And yourself. Strat. Dir. 2011, 27, 29-31.

6. Menguc, B.; Auh, S.; Yannopoulos, P. Customer and Supplier Involvement in Design: The Moderating Role of Incremental and Radical Innovation Capability. J. Prod. Innov. Manag. 2014, 31, 313-328. [CrossRef]

7. Li, M.; Kankanhalli, A.; Kim, S.H. Which Ideas are More Likely to be Implemented in Online User Innovation Communities? An Empirical Analysis. Decis. Support. Syst. 2016, 84, 28-40. [CrossRef]

8. Priem, R.L.; Li, S.; Carr, J.C. Insights and New Directions from Demand-Side Approaches to Technology Innovation, Entrepreneurship, and Strategic Management Research. J. Manag. 2012, 38, 346-374. [CrossRef]

9. Yang, X.; Li, G. Factors Influencing the Popularity of Customer-Generated Content in a Company-Hosted Online Co-Creation Community: A Social Capital Perspective. Comput. Hum. Behav. 2016, 64, 760-768. [CrossRef]

10. Hallerstede, S.H. Open Innovation Platforms: Managing the Lifecycle of Open Innovation Platforms; Springer Science \& Business Media: Boston, NY, USA, 2013.

11. Hong, J.F.L.; Zhao, X.; Snell, R.S. Collaborative-based HRM practices and open innovation: A conceptual review. Int. J. Hum. Resour. Manag. 2019, 30, 31-62. [CrossRef]

12. Chesbrough, H.; Sohyeong, K.; Agogino, A. Chez panisse: Building an Open Innovation Ecosystem. Calif. Manag. Rev. 2014, 56, 144-171. [CrossRef]

13. Kim, H.; Kim, E. How an Open Innovation Strategy for Commercialization Affects the Firm Performance of Korean Healthcare IT SMEs. Sustainability 2018, 10, 2476. [CrossRef]

14. Rossignoli, C.; Ricciardi, F.; Bonomi, S. Organizing for Commons-Enabling Decision-Making Under Conflicting Institutional Logics in Social Entrepreneurship. Group Decis. Negot. 2018, 27, 1-27. [CrossRef]

15. Lyu, Y.B.; Lan, Q.; Han, S.J. Growth Genes of Open Innovation Ecosystem: Multiple Case Studies Based on iOS, Android and Symbian. China Ind. Econ. 2015, 5, 148-160. 
16. Gassmann, O.; Schuhmacher, A.; von Zedtwitz, M.; Reepmeyer, G. The Open Innovation Challenge: How to Partner for Innovation; Springer: Cham, Switzerland, 2018.

17. Becker, B.A.; Eube, C. Open innovation concept: Integrating universities and business in digital age. J. Open Innov. Technol. Mark. Complex. 2018, 4, 12. [CrossRef]

18. Salmelin, B. The Horizon 2020 framework and Open Innovation Ecosystems. J. Innov. Manag. 2013, 1, 4-9. [CrossRef]

19. Gupta, A.; Dey, A.; Singh, G. Connecting corporations and communities: Towards a theory of social inclusive open innovation. J. Open Innov. Technol. Mark. Complex. 2017, 3, 17. [CrossRef]

20. Moskowitz, H.R.; Saguy, I.S. Reinventing the Role of Consumer Research in Today's Open Innovation Ecosystem. Crit. Rev. Food Sci. Nutr. 2013, 53, 682-693. [CrossRef]

21. León, G. Gonzalo Leon, Analysis of University-driven Open Innovation Ecosystems: The UPM Case Study. $R$ D Manag. 2013, 12, 321-336.

22. West, J.; Wood, D. Creating and Evolving an Open Innovation Ecosystem: Lessons from Symbian Ltd.; Social Science Electronic Publishing: Rochester, NY, USA, 2011.

23. Thornton, P.H.; Ocasio, W.; Lounsbury, M. Institutional Logics Perspective; Oxford University Press: Oxford, UK, 2012.

24. Durand, R.; Thornton, P. Categorizing Institutional Logics, Institutionalizing Categories: A Review of Two Literatures; Social Science Electronic Publishing: Rochester, NY, USA, 2018; Volume 12.

25. Corbett, J.; Webster, J.; Jenkin, T.A. Unmasking Corporate Sustainability at the Project Level: Exploring the Influence of Institutional Logics and Individual Agency. J. Bus. Ethics 2018, 147, 261-286. [CrossRef]

26. Thelisson, A.S.; Géraudel, M.; Missonier, A. How do institutional logics evolve over the merger process? A case in the public-private urban planning sector. Strateg. Chang. 2018, 27, 53-67. [CrossRef]

27. Zhu, Q.; Sarkis, J.; Lai, K. Institutional-based antecedents and performance outcomes of internal and external green supply chain management practices. J. Purch. Supply Manag. 2013, 19, 106-117. [CrossRef]

28. Ren, H.; Wang, R.; Zhang, S.; Zhang, A. How Do Internet Enterprises Obtain Sustainable Development of Organizational Ecology? A Case Study of LeEco Using Institutional Logic Theory. Sustainability 2017, 9, 1375. [CrossRef]

29. Dacin, M.T.; Munir, K.; Tracey, P. Formal Dining at Cambridge College: Linking Ritual Performance and Institutional Maintenance. Acad. Manag. J. 2010, 53, 1393-1418. [CrossRef]

30. Lawrence, T.B.; Suddaby, R. Institutions and institutional work. Sage Handb. Organ. Studies. 2009, $215-254$. [CrossRef]

31. Nicolini, B. Re-reading the role of Oman within its International Trade Relations from 16th to the 19th centuries. In Regionalizing Oman. Political, Economic and Social Dynamics; Wippel, S., Ed.; Springer Science: Dordrecht, The Netherlands, 2013; pp. 149-157.

32. Lindberg, K. Performing multiple logics in practice. Scand. J. Manag. 2014, 30, 485-497. [CrossRef]

33. Mcpherson, C.M.; Sauder, M. Logics in Action Managing Institutional Complexity in a Drug Court. Adm. Sci. Q. 2013, 58, 165-196. [CrossRef]

34. Thornton, P.H. The Institutional Logics Perspective: A New Approach to Culture, Structure, and Process; Oxford University Press on Demand: New York, NY, USA, 2012; Volume 15, pp. 145-147.

35. Gobble, M.A.M. Charting the Innovation Ecosystem. Res. Technol. Manag. 2014, 57, 55-59.

36. Estrin, J. Closing the Innovation Gap: Reigniting the Spark of Creativity in a Global Economy. Bus. Horiz. 2008, 52, 513-514.

37. Trott, P.; Hartmann, D. Why 'Open Innovation' Is Old Wine in New Bottles. Int. J. Innov. Manag. 2009, 13, 715-736. [CrossRef]

38. West, J.; Bogers, M. Leveraging External Sources of Innovation: A Review of Research on Open Innovation. Soc. Sci. Electron. Publ. 2014, 31, 814-831. [CrossRef]

39. Rohrbeck, R.; Hölzle, K.; Gemünden, H.G. Opening up for competitive advantage-How Deutsche Telekom creates an open innovation ecosystem. $R$ D Manag. 2010, 39, 420-430. [CrossRef]

40. Tian, C.H.; Ray, B.K.; Lee, J. BEAM: A Framework for Business Ecosystem Analysis and Modeling. IBM Syst. J. 2008, 47, 101-114. [CrossRef]

41. Yamakami, T. A Three-Dimension Analysis of Driving Factors for Mobile Application Stores: Implications of Open Mobile Business Engineering. In Proceedings of the IEEE Workshops International Conference on Advanced Information Networking \& Applications, Singapore, 22-25 March 2011. 
42. Eisenhardt, K.M.; Graebner, M.E. Theory Building from Cases: Opportunities And Challenges. Acad. Manag. J. 2007, 50, 25-32. [CrossRef]

43. Eisenhardt, K.M. Building Theories from Case Study Research. Acad. Manag. Rev. 1989, 14, 532-550. [CrossRef]

44. Yin, R.K. Case Study Research Design and Methods; Blackwell Science Ltd.: London, UK, 2013.

45. Patton, M.Q. Qualitative Evaluation and Research Methods; Sage Publications, Inc.: Thousand Oaks, CA, USA, 1990.

46. Brodsky, C.M. The Discovery of Grounded Theory: Strategies for Qualitative Research-Psychosomatics. Am. J. Sociol. 2012, 3, 377-380. [CrossRef]

47. Huberman, A.M.; Miles, M.B. Data management and analysis methods. In Handbook Qualitative Research, 2nd ed.; Sage Publications, Inc.: Thousand Oaks, CA, USA, 2000; pp. 428-444.

48. Glaser, B.G.; Strauss, A.L. The purpose and credibility of qualitative research. Nurs. Res. 1966, 15, 56-61. [CrossRef]

49. Gawer, A.; Cusumano, M.A. Industry Platforms and Ecosystem Innovation. J. Prod. Innov. Manag. 2013, 31, 417-433. [CrossRef]

50. Benhamou, E.; Eisenberg, J.; Katz, R.H. Assessing Changing U.S. IT RED Ecosystem; ACM: New York, NY, USA, 2010.

51. Adner, R.; Kapoor, R. Value creation in innovation ecosystems: How the structure of technological interdependence affects firm performance in new technology generations. Strateg. Manag. J. 2010, 31, 306-333. [CrossRef]

52. Micelotta, E.; Lounsbury, M.; Greenwood, R. Pathways of institutional change. J. Manag. 2017, 43, $1885-1910$.

53. Bettis, R.A.; Prahalad, C.K. The dominant logic: Retrospective and extension. Strateg. Manag. J. 1995, 16, 5-14. [CrossRef]

54. Suddaby, R.; Greenwood, R. Leading Change in the New Professional Service Firm: Characterizing Strategic Leadership in a Global Context. Res. Sociol. Organ. 2006, 24, 101-137.

55. Nigam, A.; Ocasio, W. Event Attention, Environmental Sensemaking, and Change in Institutional Logics: An Inductive Analysis of the Effects of Public Attention to Clinton's Health Care Reform Initiative. Organ. Sci. 2010, 21, 823-841. [CrossRef]

56. Schweisfurth, T.G. Comparing internal and external lead users as sources of innovation. Res. Policy 2017, 46, 238-248. [CrossRef]

57. Shah, S.K. Motivation, Governance, and the Viability of Hybrid Forms in Open Source Software Development. Manag. Sci. 2006, 52, 1000-1014. [CrossRef]

58. Traitler, H.; Watzke, H.J.; Saguy, I.S. Reinventing R\&D in an open innovation ecosystem. J. Food Sci. 2011, 76, R62. [PubMed]

59. Lancker, J.V.; Wauters, E.; Huylenbroeck, G.V. Open Innovation in Public Research Institutes-Success and Influencing Factors. Int. J. Innov. Manag. 2019, 2019, 1950064. [CrossRef] 